\title{
BUDAYA BETANGKANT ANAK DALAM SUKU DAYAK KENINJAL SEBAGAI UPAYA KONTEKTUALISASI KASIH ALLAH
}

\author{
Herwinesastra \\ Sekolah Tinggi Teologi Pontianak \\ JL. Perintis Gang Remaja 2, Melayu Laut Pontianak Selatan, Kota Pontianak, Kalimantan Barat 78123 \\ Email: herwine_sastra@yahoo.com
}

\begin{abstract}
Herwinesastra. The purpose of this paper is to analyze a Betinak Dayak Keninjal Children's culture as an attempt to contextualize the love of God. The study of the meaning and cultural aspects of raising children in an effort to apply the gospel or good news in the context of the life of the Dayak Keninjal community. Through the Betangkant Anak culture in the Keninjal tribe, the village of Madyaraya will give meaning and an entrance to evangelism for Dayak Keninjal to know Jesus Christ as Lord and Savior in the tribe of Keninjal and represent the relationship between the Father and the believers. Trusting children can make it easier to communicate God's relationship with His people like the relationship between a father and a child who has been raised in a culture of tension. Affirmation of the relationship between the Father and His Children has been manifested in the love of God the Father through the sacrifice of the Lord Jesus Christ to redeem and lift believers into His beloved children.
\end{abstract}

Keywords: Contextual, Gospel, Culture, Betangkant Children, Dayak Keninjal

\begin{abstract}
Abstrak: Herwinesastra. Tujuan penulisan ini adalah untuk menganalisis sebuah budaya betangkant Anak Dayak Keninjal sebagai upaya kontekstualisasi kasih Allah. Pengkajian aspek arti dan nilai budaya mengangkat anak dalam upaya penerapan Injil atau kabar baik dalam kontek kehidupan masyarakat Dayak Keninjal. Melalui budaya betangkant Anak di suku Keninjal, desa Madyaraya akan memberikan makna dan pintu masuk penginjilan bagi suka Dayak Keninjal untuk mengenal Yesus Kristus sebagai Tuhan dan Juruselamat dalam suku Keninjal serta representai hubungan antara Bapa dan orang-orang percaya. Dengan betangkant anak dapat memudahkan untuk mengkomunikasi hubungan Allah dengan umat-Nya seperti hubungan antara seorang Bapak dengan anak yang sudah diangkat dalam budaya betangkant. Peneguhan hubungan antara Bapa dan Anak-Anak-Nya telah diwujudkan dalam kasih Allah Bapa melalui pengorbanan Tuhan Yesus Kristus untuk menebus dan mengangkat orang-orang percaya menjadi anak-anak kesayangan-Nya.
\end{abstract}

Kata Kunci: Kontekstual, Injil, Budaya, Betangkant Anak, Dayak Keninjal.

\section{PENDAHULUAN}

Kebudayaan sangat erat hubungannya dengan masyarakat yang akan mempengaruhi seluruh tata cara kehidupan manusia dalam masyarakat atau golongan tertentu yang dianggap lebih tinggi atau yang diinginkan yang meliputi cara berperilaku, bekerpercayaan, bersikap, dan memiliki persamaan hingga dapat dibedakan dengan masyarakat lain. Dengan demikian kebudayaan berarti kumpulan pengetahuan yang sama-sama dimiliki oleh anggota satu kelompok (Hesselgrave \& Rommen, 2015, p. 192). Perwujudan kebudayaan adalah ketika hasil karya sebuah masyarakat berupa kebiasaan yang dilakukan terus menerus serta diaktualisiasikan untuk menca- pai tujuan masyarakat tersebut untuk melangsungkan kehidupannya. Dari sudut lain, teologi kontekstualisasi adalah refleksi ideal dari setiap orang Kristen dalam konteks hidupnya atas Injil Yesus Kristus (Tomatala, 1996, p. 2).

Sebuah penelitian yang mengungkapkan pemanfaatan kebudayaan untuk kontekstualisasi Injil dilakukan oleh Siswanto (2017). Dalam penelitiannya, mengemukakan kontekstualisasi Injil menggunakan budaya Jawa Timuran. Hasil penelitiannya menunjukkan bahwa GKII Pulerejo, Madiun mengembangkan pendekatan kontekstual menggunakan budaya Jawa Timur dengan tetap berlandaskan prinsip-prinsip iman Kristen (Siswanto, 2017, p. 61). 
Pola pendekatan kontekstual untuk mengomunikasikan Injil tampaknya dapat dilakukan dengan menggunakan kebudayaan lokal.

Provinsi Kalimantan Barat juga merupakan salah satu provinsi di Kalimantan yang memiliki banyak ragam sub suku dayak. Diperkirakan Kalimantan Barat memiliki suku-suku dayak yang terbanyak. Pada satu kabupaten saja ditemukan lebih dari 30 suku dayak yang memiliki tradisi dan budaya masingmasing, dan saling berbeda. Suku Dayak Keninjal adalah salah satu suku Dayak yang ada di Kalimantan Barat. Sebelum Injil masuk yang dibawa oleh misionaris, kepercayaan Suku Dayak Keninjal adalah animisme dan dinamisme. Nama-nama dan tempat yang diagungkan oleh suku Dayak Keninjal adalah disebut Sebayat sebagai penguasa udara atau alam, sedangkan sebagai penguasa tanah dan roh pertanian adalah Piyang Gana, dalam upacara untuk memanggil roh-roh yang sudah meninggal dalam budaya Keninjal disediakan tempat untuk pemujaan seperti di pohon-pohon besar, batu-batu besar, atau pun dalam bentuk patung yang disebut dengan istilah Temaduk (Martono, 2010, p. 150). Salah satu budaya yang masih dipertahankan dan dilaksanakan sampai hari ini adalah budaya mengangkat anak. Kebiasaan ini menarik dan terus dijaga sampai sekarang. Kebiasaan ini terus dilakukan dari nenek moyang orang Dayak Keninjal sampai hari ini di tengah-tengah perubahan zaman yang semakin modern dalam masyarakat Dayak Keninjal.

Penelitian relevan terhadap suku dayak Keninjal dilakukan oleh Martono (2010) yang melakukan penelitian terhadap sistem religi sastra lisan Dayak Keninjal. Sementara penelitian yang dilakukan oleh Juliarsa, Saman, dan Hanye (2014) lebih menyoroti afiksasi bahasa Dayak Keninjal. Penelitian lain dilakukan oleh Kusnawati, Martono, dan Syam (2016) yang meneliti tentang nilai moral dan fungsi cerita tima dan nima cerita rakyat Dayak Keninjal Kabupaten Melawi. Kemudian penelitian yang dilakukan oleh Martono (2018) yang melakukan penelitian tentang nilai-nilai sosial dalam "Batu Dara $\mathrm{Mu}$ ning" pada literatur oral suku Dayak Keninjal. Pe- nelitian tersebut lebih menekankan pada sistem religi, kemudian cerita rakyat, dan nilai-nilai sosial dalam literatur oral Dayak Keninjal. Selanjutnya penelitian yang dilakukan oleh Idayani, Hanye, dan Patriantoro (2018) lebih menekankan pada kajian semantik terhadap peribahasa Dayak Keninjal. Sementara penelitian yang penulis lakukan lebih menekankan pada upaya kontekstualisasi Injil melalui budaya mengangkat anak pada suku Dayak Keninjal.

Dalam pelaksanaan upacara budaya Betangkant anak diharapkan akan adanya nilai-nilai dan makna yang dapati digunakan untuk menyadari kasih Allah yang besar bagi umat manusia. Namun kenyataannya masih ada beberapa orang Kristen suku Dayak Keninjal dalam pelaksanaan upacara Betangkant anak tidak disadari oleh orang Kristen suku Dayak Keninjal sebagai wujud nyata bahwa betangkant anak juga merupakan wujud kasih umat manusia kepada sesama.

Rumusan masalah penelitian ini adalah bagaimana upaya kontekstualisasi kasih Allah melalui budaya betangkant anak di Suku Dayak Keninjal, Tanah Pinoh? Tujuan penelitian ini adalah untuk menganalisis sebuah upaya kontekstualisasi Kasih Allah melalui budaya betangkant anak di Suku Dayak Keninjal, Desa Madyaraya.

\section{METODE}

Penelitian ini dilakukan di desa Madyaraya Kecamatan Sayan Kabupaten Melawi Kalimantan Barat. Desa ini dipilih mengingat hampir seluruh warga desa adalah suku Dayak Keninjal. Moleong (2012, p. 82) menyatakan bahwa dengan metode deskriptif data-data yang berupa kata-kata, gambaran dan bukan angka-angka sehingga laporan penelitian akan berisi kutipan-kutipan data yang objektif. Bentuk penelitian adalah penelitian kualitatif yaitu penelitan yang menghasilkan data-data deskriptif yang mengungkapkan pendapat/tanggapan masyarakat tentang pengertian, makna dan nilai yang dikandung dalam budaya betangkan anak.

Pendekatan kontekstualisasi memiliki model yang beragam. Model ini tentu dibangun di atas fon- 
dasi kontekstualisasi yang Alkitabiah. Kontekstualisasi teologi adalah upaya untuk memahami iman Kristen dipandang dari segi suatu konteks tertentu (Bevans, 2002, p. 1). Pendekatan terhadap budaya mengangkat anak di suku Dayak Keninjal adalah dengan mengunakan model Akomodasi. Model Akomodasi adalah sebuah sikap menghargai dan terbuka terhadap budaya asli yang dilakukan dalam sikap, kelakuan, dan pendekatan praktis dalam tugas misionaris baik secara teologi maupun secara ilmiah. Obyek Akomadasi adalah kehidupan budaya yang menyeluruh dari suatu bangsa dari segi fisik, sosial maupun ideal (Tomatala, 1996, p. 77). Di sini dapat dilihat bahwa secara holistik keberhasilan model Akomodasi ditentukan oleh peran aktif seorang misionaris dalam upaya pendekatan kontekstual Injil. Dalam proses ini terjadi perpaduan nilai hidup Kristiani di mana Kristus menjadi penyempurnaan dan pelengkap aspirasi budaya. Dengan demikian akan terdapat sikap positif terhadap Injil.

\section{HASIL DAN PEMBAHASAN}

\section{Konteks Budaya Mengangkat Anak Bagi Suku Dayak Keninjal}

Kontek budaya adalah kumpulan pengetahuan dan perilaku bahasa yang sama-sama dimiliki oleh sejumlah kelompok atau masyarakat. Budaya mencakup keseluruhan sistem dari prinsip-prinsip budaya, pola-pola komunikasi antar masyarakat dan bentuk-bentuk perilaku yang diterima dalam suatu budaya tertentu (Hesselgrave \& Rommen, 2015, p. 200). Dalam konteks budaya Suku Dayak Keninjal ada sebuah kebiasaan betangkan. Budaya Betangkant adalah: budaya Dayak mengangkat atau mengambil; orang tua, anak, saudara sebagai bagian dari keluarga yang mengangkatnya maupun yang di angkat sebagai ahli waris dalam keluarga yang Betangkant. (Undang-Undang Adat Istiadat dan Hukum Adat Dayak Kabupaten Melawi, 2015).

Ada beberapa jenis Betangkat diantaranya adalah: betangkant apak, betangkant umak, betangkant empala, dan betangkant anak, yang dimaksud- kan dengan nangkant apak adalah seorang yang masih muda mengangkat orang yang lebih tua sebagi bapaknya atau orang tua bagi yang muda disebut betangkant apak, atau seorang muda baik laki-laki atau perempuan mengangkat orang tua sebagi ibu kandungnya di sebut nangkant umak. Sedangkan anak muda mengangkat anak muda sebagai saudaranya disebut betangkant empala. Kalau orang yang lebih tua mengangkat orang muda atau anak-anak maka di sebut nangkant anak.

Guna mendapatkan informasi yang jelas penulis melakukan wawancara langsung dengan $T e$ manggung (Kepala Adat Suku Dayak Keninjal Kecamatan Sayan, Kabupaten Melawi, Kalimantan Barat) yaitu Bapak Apel dan Seorang Tokoh Masyarakat di Desa Madyaraya yaitu Bapak Elius Badong pada hari Kamis, 17 November 2016, menjelaskan dengan lengkap bagaimana asal-usul budaya mengangkat anak. Dalam budaya Suku Dayak Keninjal secara khusus yang mendiami Daerah Tanah Pinoh Kecamatan Sayan Kabupaten Melawi Kalimantan Barat, secara khusus di Desa Madyaraya bahwa budaya betangkant anak didasari dari dua proses, yaitu yang pertama ketika seorang bermimpi tentang anak itu maka perlu ditindaklanjuti dengan cara memanggil kepala adat atau tokoh masyarakat untuk menyaksikan dan yang kedua adalah ketika ada keluarga atau pribadi melihat seseorang yang memiliki sikap dan perilaku yang menarik lalu ingin menjadikan seseorang ini menjadi anak atau orang tuanya (Apel, Wawancara, 17 Nopember 2016).

Asal usul betangkant dimulai dari peristiwa seorang Bapak yang bernama Mamat, Suku Dayak Keninjal yang gemar berburu ke hutan rimba dengan alat sumpitnya. Perjalanan yang panjang dan jauh menyebabkan si Mamat tidak sampai kepada tujuan sehingga harus bermalam di tengah-tengah hutan. Ketika sedang tidur di atas tanah, tiba-tiba si Mamat bermimpi bertemu dengan roh bapaknya yang sudah meninggal. Roh dari bapak Mamat ini berkata bahwa anak dari adiknya perempuan harus diserahkan kepada Mamat karena anak ini sering mengalami sakit penyakit, jika tidak diberi maka anak ini akan 
selalu sakit. Ketika Mamat pulang sampai di rumah, si Mamat langsung menceritakan kepada istrinya (Apel, Wawancara, 17 Nopember 2016). Lalu Mamat dan istrinya datang ke rumah adik Mamat yang perempuan dan menyampaikan bahwa dia bermimpi bertemu dengan roh bapaknya dan isi dalam mimpi itu adalah bahwa anak adiknya perempuan akan diangkat menjadi anak Mamat supaya anak ini tidak sering sakit-sakitan. Akhirnya si Mamat memberikan kepada orangtua anak ini satu gantang beras, seekor ayam dan sepasang pakaian serta sebuah parang kepada adik perempuannya (Apel, Wawancara, 17 Nopember 2016). Setelah kejadian itu anak itu tidak lagi menjadi sakit dan memanggil si Mamat dengan panggilan bapak tua dan istri Mamat dengan panggilan mama tua. Inilah asal usul budaya betangkant anak di Dayak Keninjal daerah Tanah Pinoh. Tidak hanya orang tua yang mengangkat anak menjadi anaknya, ada juga anakanak yang sudah dewasa ketika senang melihat orang tua maka atas dasar keinginan hati mengangkat orang tua itu sebagai orang tua dengan membayar adat seperti orang tua mengangkat seseorang menjadi anak angkatnya. (Apel, Wawancara, 17 Nopember 2016).

\section{Proses-Proses Terjadinya Betangkant Anak Dalam Budaya Keninjal}

Adapun budaya betangkant dilaksanakan turun-temurun oleh suku Dayak Keninjal desa Madyaraya, yang dimulai dengan adanya tanda-tanda yang menyertai sehingga terjadinya upacara betangkant anak. Tanda pertama adalah jika seorang bapak atau seorang ibu bermimpi menjumpai seorang anak yang sedang hanyut di sungai atau tersesat di hutan lalu seseorang menolong anak itu, maka haruslah mimpi itu disampaikan ke keluarga yang memiliki anak tersebut dan membawa pengurus desa atau kepala adat untuk melaksanakan upacara nangkat anak. Dalam konteks masa kini upacara atau acara nangkat anak melibatkan gembala sidang atau pendeta yang melayani di daerah tersebut dan pendeta atau hamba Tuhan akan menumpangkan tangan untuk mendoa- kan sehingga dalam proses inilah Injil masuk untuk disampaikan kepada orang-orang Dayak yang hadir bahwa nangkat anak sama seperti yang ada di dalam Alkitab bahwa Allah mengangkat manusia yang berdosa untuk diselamatkan dari kebinasaan.

Tanda kedua yang terjadi pada masa kini adalah bahwa jika seseorang merasa nyaman, suka dan dekat dengan seseorang maka orang tersebut bisa menyampaikan kepada keluarga dari anak tersebut untuk menyatakan keinginan untuk betangkant menjadi anaknya dengan melaporkan kepada pengurus adat atau Gembala Sidang di kampung tersebut.

Pada masa lalu upacara betangkant dilakukan sebagai sebuah prosesi betangkant keluarga. Pihak yang ingin betangkant membuat acara dengan cara mengundang masyarakat adat yang ada di desanya berkumpul bersama dalam rumah atau balai pertemuan untuk melaksanakan upacara betangkant sebagai bukti atau saksi bahwa mereka betangkant dan mereka adalah satu kesatuan dalam keluarga yang batangkant. Setelah masyarakat adat berkumpul di rumah yang betangkant, maka pengurus adat yang diberi gelar Temenggung melaksanakan tata cara pertangkantan itu yang dimulai dengan membaca adat betangkant sebagai mana yang telah diatur dalam buku adat istiadat, hukum adat yang telah disahkan oleh bagian Hukum dan HAM sekretariat daerah Kabupaten Melawi dengan rincian adatnya sebagai berikut; sebuah tempayan kenaruh semongat, satu helai kebilai (selembar kain panjang) atau selimut, sehelai baju (sepasang pakaian), satu bilah isau (parang), bosi pekoras dan adat betangkant sebesar 2 (dua real permas) dikalikan 100.000/real sama dengan $\mathrm{Rp}$ 200,000 (dua ratus ribu rupiah). Setelah pembacaan adat dilakukan, acara kedua yaitu: serah terima adat yang diserahkan dari yang mengangkat kepada yang diangkat. Sedangkan acara ketiga, kedua pihak betangkant, beturih darah yang dilambangkan dengan makan sirih, kapur dan pinang yang disebut makan peminang yang melambangkan bahwa darah yang mengangkat telah bersatu dengan darah yang diangkat. Adat ini diyakini oleh masyarakat adat dayak bahwa kedua pihak betangkant 
tidak boleh berpisah, tidak bolah berkhianat, tidak boleh berbuat jahat. Apabila salah satu mengabaikan ikatan perjanjian itu, maka diyakini oleh masyarakat bahwa yang melanggarnya akan kena kutuk. Kemudian, acara keempat, kedua pihak betangkant makan bersama secara teratur yang dihidangkan oleh pelayan-pelayan.

\section{Makna-Makna Adat yang di Siapkan dalam Upacara Betangkant Anak}

Proses praktik upacara betangkant anak yang dilakukan dalam budaya Dayak Keninjal dimulai dengan adanya kesepakatan antara orang yang ingin betangkant dengan keluarga yang memiliki anak. Kesepakatan tersebut meliputi, kesepakatan untuk mengundang tokoh adat dan masyarakat, pendeta atau gembala sidang untuk menyaksikan upacara betangkant dan kesepakatan untuk memberkan beberapa benda dari orang yang akan mengangkat anak (betangkant anak) kepada anak yang akan diangkat menjadi anaknya. Wawancara penulis dengan Ketua Dewan Adat Daerah Melawi Periode 2015-2020, Sudarmono Otong, mengemukakan bahwa syarat-syarat dalam upacara betangkan anak sudah dibuat atau diatur dalam buku Dewan Adat Dayak Kabupaten Melawi.

Makna dari barang-barang yang diserahkan dalam upacara betangkant anak memiliki arti atau makna masing-masing, seperti yang penulis pernah saksikan dalam upacara betangkant anak adalah: 1) Baju Peniningk Kulit atau sepasang pakaian. Dengan memberikan pakaian ini menandakan bahwa anak ini telah mendapatkan perlindungan dan ada tanggungjawab dari pihak yang petangkant; 2) Sengkolan (seekor Ayam). Darah seekor ayam yang telah dipotong akan dioleskan sedikit di kening anak yang akan ditangkant sebagai tanda atau simbol bahwa anak ini telah sah diangkat menjadi anak. Darah melambangkan adanya perjanjian antara anak yang ditangkant dengan orang yang menangkant menjadi sebuah ingkatan yang sah menurut adat Suku Dayak Keninjal; 3) Beras Pengugur (seadanya). Beras melambangkan sesuatu yang disukai se- mua orang dan memberi penghidupan bagi Suku Dayak Keninjal. Dengan memberi Beras ada sebuah harapan bahwa kehidupan bagi anak ini akan terus berlangsung; 4) Bosi Pekoras atau sebuah parang yang melambangkan bahwa anak yang ditangkant akan kuat, tidak mudah menyerah dalam keadaan apapun serta bertahan terhadap segala tantangan dan persoalan dalam kehidupan. (Undang-Undang Adat Istiadat dan Hukum Adat Dayak Kabupaten Melawi Kalimantan Barat, 2015).

\section{Makna Dalam Betangkant Anak}

Kebudayaan ialah segala sesuatu yang diciptakan oleh budi manusia, yaitu segala sesuatu yang dipikirkan, diusahakan, serta dikerjakan oleh manusia dalam lingkup (konteks) hidupnya secara utuh dan menaklukkan alam memenuhi kebutuhan-kebutuhannya (Tomatala, 1996, p. 52). Dalam budaya betangkant anak yang dilakukan oleh masyarakat Dayak Keninjal memiliki sebuah arti atau nilai-nilai yang diyakini sebagai sebuah usaha untuk dapat memiliki harapan masa depan yang lebih baik. Sehingga budaya pengangkatan anak dilakukan terusmenerus dan dihidupi dalam masyarakat Dayak Keninjal yang dilakukan ketika ada kegiatankegiatan hari raya umat Kristen seperti Paskah dan Natal di daerah. Adapun nilai-nilai yang diyakini oleh Suku Dayak Keninjal ketika sudah melaksanakan upacara mengangkat anak adalah: 1) Dengan diangkatnya seorang anak, diyakini bahwa jika anak itu sering mengalami sakit, maka anak itu menjadi tidak sakit lagi, adanya rasa aman serta rasa perlindungan dalam diri anak karena ada orang tua angkat yang bisa menopang jika anak ini bertumbuh dan untuk mencapai cita-citanya. Pengalaman ini juga terjadi dengan penulis, ketika anak penulis yang baru berusia 10 bulan jatuh sakit dan dirawat di rumah sakit, ada seorang sahabat penulis yang ingin menjadi orang tua angkat bagi anak penulis. Lalu setelah pulang dari rumah sakit, penulis melaksanakan upacara betangkant anak sehingga anak penulis merasa ada orang tua lain yang terus memberikan perhatian khusus kepadanya. Dampak 
yang sering terjadi di Suku Dayak Keninjal, jika orang tua angkat ini memiliki dana maka akan membantu biaya hidup anak, baik ketika anak ini ingin melanjutkan pendidikan sampai kepada pernikahan. Bentuk dan wujud yang diberikan adalah dengan memberi bantuan berupa uang, harta warisan seperti tanah, kebun dan lain-lain; 2) Bagi keluarga yang akan mengangkat seseorang menjadi anaknya, mengandung sebuah harapan bahwa suatu kelak anak ini akan menjadi bagian keluarga yang akan meneruskan estafet kehidupan keluarga serta akan mewarisi apa yang menjadi milik keluarga jika keluarga ini tidak memiliki anak kandung bahkan akan merawat orang tua ini ketika di usia lanjut.

Dengan demikian adat betangkant anak bagi suku Dayak Keninjal di daerah Tanah Pinoh adalah memberi sebuah nilai atau arti dalam mempertahankan dan melanjutkan kehidupan sebuah keluarga. Dalam iman Kristen, hal ini adalah sebuah tindakan Allah dalam menebus dan menjadikan manusia berdosa menjadi anak-anak Allah atas Kasih Anugerah Allah bagi manusia yang berdosa serta memelihara ciptaan-Nya dengan sempurna.

\section{Pendekatan Kontekstualisasi Kasih Allah}

Dalam Alkitab, khususnya Perjanjian Lama tidak ada hukum yang mengatur mengenai mengangkat anak. Namun dalam Perjanjian Lama ada bagian yang menunjukkan tindakan mengangkat anak, yaitu: Kejadian 15:2-3 mengatakan: "Abraham menjawab: ya Tuhan Allah, apakah yang akan engkau berikan kepadaku, karena aku akan meninggal dan tidak mempunyai anak, dan yang akan mewarisi rumahku ialah Eliezer orang Damsik itu." Lagi kata Abraham; Engkau tidak memberikan kepadaku keturunan sehingga seorang hambaku nanti menjadi ahli warisku. Ayat ini menegaskan bahwa Abraham betangkant dengan Eliezer. Abraham mengangkat Eliezer sebagai anak (mengadopsi) untuk mempertahankan katurunan dan menjadi ahli waris Abraham. Demikian juga yang dilakukan oleh Putri Firaun mengambil Musa (Kel. 2:10). Sebagai anak yang diangkat oleh Abraham, Eliezer akan di- siapkan untuk menjadi penerus bahkan ahli waris Abraham. Kepada Eliezer akan diserahkan pemeliharaan keluarga dan harta milik Abraham. Dengan demikian betangkant anak adalah sebuah tradisi yang telah dilakukan oleh tokoh-tokoh dalam Perjanjian Lama.

Dasar Alkitab dalam Perjanjian Baru Roma 8:14-15. Semua orang yang dipimpin Roh Allah, adalah anak Allah. Sebab kamu tidak menerima roh perbudakan, yang membuat kamu menjadi takut lagi, tetapi kamu telah menerima Roh yang telah menjadikan kamu anak Allah. Oleh roh itu kita berseru Ya Aba Ya Bapa. Dalam Galatia 4:6 dituliskan “dan karena kamu adalah anak, maka Allah telah menyuruh Roh Anak-Nya kedalam hati kita yang berseru Ya Aba Ya Bapa.” Kemudian dalam Markus 14:36 dituliskan "Kata-Nya: Ya Aba Ya Bapa tidak ada yang mustahil bagi-Mu, ambillah cawan ini dari pada-Ku, tetapi jangan apa yang Aku kehendaki, melainkan apa yang Engkau kehendaki." Dari dua teks tersebut, secara teologis batangkant merupakan tindakan Allah terhadap orang yang percaya dengan memberi mereka Roh Kudus, Roh dari betangkant setiap orang percaya telah diadopsi menjadi anakanak Allah secara rohani (Gal. 3:16; 4:5, Ef 1:5). Secara teologis kasih karunia Allah merupakan dasar batangkant (adopsi manusia menjadi anak-Nya. Dalam Perjanjian Baru di dalam karya keselamatan di dalam Tuhan Yesus, setiap orang percaya telah menjadi anak-anak Allah oleh karena kasih karunia. Menurut teologi Kristen, Allah mengangkat setiap orang percaya untuk menjadi anak-anak-Nya. Betangkant ini terjadi karena anugerah Allah. Bagi umat percaya, masalah betangkant anak merupakan pernyataan iman manusia kepada Tuhan melalui tindakan mengasih sesama manusia. Tuhanlah yang melakukan pengangkatan anak kepada manusia, dengan menunjukkan kuasa-Nya dan kasih-Nya melalui penebusan oleh Kristus di kayu salib. Dengan peristiwa tersebut, maka setiap orang yang percaya telah menjadi anak-anak-Nya, sesuai dengan kemurahan dan kehendak-Nya (Ef. 1:5). Berdasarkan gambaran tersebut, budaya betangkant anak 
sama seperti yang yang dilakukan Allah dalam menerima dan mengangkat manusia menjadi anakanak-Nya melalui kasih karunia di dalam Tuhan Yesus.

Dengan demikian secara etis anak yang diangkat telah mendapat kasih sayang yang penuh dari orang tua yang mengangkatnya sebagaimana Allah telah mengangkat manusia menjadi anak-anak-Nya dan tidak melecehkan manusia tersebut, demikian juga-lah orang yang mengangkat anak melakukan apa yang dikehendaki Allah. Dengan demikian akan terdapat pandangan yang baik terhadap budaya betangkant anak di desa Madyaraya dalam budaya suku dayak Keninjal berdasarkan iman kristen terhadap anugerah Allah kepada orang-orang percaya. Pada umumnya, kontekstualisasi dilihat sebagai suatu istilah yang memaparkan tentang suatu proses dimana berita tentang iman Kristen dibuat menjadi relevan dan berarti bagi budaya yang menjadi penerima berita tersebut. Dalam budaya betangkant di desa Madyaraya melalui upacara ini bahwa media-media yang dipakai melalui beberapa simbol tidak lagi menggunakan benda atau alat-alat tersebut tetapi diganti dengan ibadah yang dipimpin oleh hamba Tuhan atau gembala setempat dengan menggunakan Alkitab sebagai pedoman dan petuah bahwa Allah sendiri yang menjadi baju penining kulit, dalam hal ini menjaga dan memelihara dengan sempurna bagi seorang anak yang akan diangkat dalam upacara betangkant.

Sengkolan (seekor Ayam) atau darah ayam yang telah disembelih akan dioleskan sedikit di kening si anak yang akan ditangkant sebagai tanda atau simbol bahwa anak tersebut telah sah diangkat. Darah melambangkan sebuah perjanjian antara anak dengan orang tua sebagai sebuah ikatan yang sah dalam adat suku dayak Keninjal, dalam bagian ini melalui kesaksian Alkitab bahwa darah Kristus berkuasa dan telah dikorbankan dan mengikat Perjanjian Baru bagi semua umat Allah menjadi anakanak-Nya. (Undang-Undang Adat Istiadat dan $\mathrm{Hu}-$ kum Adat Dayak Kabupaten Melawi, 2015).
Beras Pengugur (seadanya). Beras melambangkan sesuatu yang disukai semua orang dan memberi penghidupan bagi suku dayak Keninjal. Dengan memberi Beras ada sebuah harapan bahwa kehidupan bagi anak yang ditangkant akan terus berlangsung. Dengan demikian beras penggugur tidak lagi digunakan tetapi diganti dengan karya Roh Kudus dalam kehidupan seseorang secara khusus anak yang ditangkant akan disukai Allah dan manusia jika hidupnya senantiasa dituntun oleh Roh Kudus. Undang-Undang Adat Istiadat dan Hukum Adat Dayak Kabupaten Melawi, 2015).

Bosi Pekoras (1 bilah parang). Dengan memberikan besi ini sebagai tanda bahwa anak ini akan kuat, tidak mudah menyerah dalam keadaan apapun serta bertahan terhadap segala tantangan dan persoalan dalam kehidupan. Dengan menjelaskan kebenaran Firman Tuhan bahwa yang membuat kehidupan anak ini tetap kuat bukan lagi bergantung kepada sebuah parang tetapi lebih utama lagi adalah bergantung kepada berkat Tuhan di dalam kehidupannya.

Dengan demikian upacara betangkant anak di desa Madyaraya tidak lagi dengan menyiapkan benda-benda seperti dalam kebiasaan adat selama ini tetapi lebih kepada persekutuan dimana proses upacara-upacara yang selama ini dipimpin pengurus adat atau kepala suku pada masa sekarang diserahkan kepada seorang hamba Tuhan atau gembala sidang. Melalui ibadah betangkant anak inilah peluang kabar baik yaitu Injil diberitakan kepada semua keluarga besar yang hadir dalam upacara ini dan di dalamnya keluarga besar yang melaksanakan budaya upacara betangkant anak akan mengenal Allah sebagai Pencipta dan Penebus hidup seluruh umat manusia serta memiliki iman yang kuat dan selalu dituntun oleh gembala sidang atau hamba Tuhan untuk tetap setia beribadah dan pada akhirnya terlibat didalam pelayanan digereja.

\section{KESIMPULAN}

Betangkant merupakan sebuah budaya yang terus menerus dilaksanakan sampai saat ini oleh 
Suku Dayak Keninjal di desa Madyaraya. Budaya yang dilaksanakan ini adalah sebagai sebuah upaya pendekatan kontekstual kasih Allah agar orangorang di Suku Dayak Keninjal secara khusus di Desa Madyaraya dapat mengetahui bahwa Allah telah mengasih mereka dan wujud kasih Allah adalah ketika mengangkat manusia yang berdosa menjadi anak-anak kesayangan-Nya. Dalam praktik budaya betangkant anak ini telah diterima oleh gereja melalui para gembala sidang yang melayani dengan diwujudkan bahwa acara betangkant anak masa kini

\section{KEPUSTAKAAN}

Apel, Wawancara Oleh Penulis, Desa Madyaraya, Kabupaten Melawi, Kalimantan Barat, 17 November 2016.

Bevans, S.B. 2002. Model-Model Teologi Kontekstualisasi. Maumere: Penerbit Ledalero STFK.

Elius Badong, Wawancara Oleh Penulis, Desa Madyaraya, Kabupaten Melawi, Kalimantan Barat, 17 November 2016.

Hesselgrave, D.J. \& Rommen, E. 2015. Kontekstualisasi Makna, Metode, dan Model. Jakarta: BPK GunungMulia.

Idayani, T. Hanye, P. \& Patriantoro. 2018. "Peribahasa Dayak Keninjal: Kajian Semantik.” Jurnal Pendidikan dan Pembelajaran, 7 (9): 1-13,

http://jurnal.untan.ac.id/index.php/jpdpb/arti cle/view/27896/75676578086

Juliarsa, Saman, S. \& Hanye, P. "Afiksasi Bahasa Dayak Keninjal." Jurnal Pendidikan dan Pembelajaran, 3 (6): 1-13, http://jurnal.untan.ac.id/index.php/jpdpb/arti cle/view/5975/6059

Kusnawati, Martono, \& Syam, C. 2016. "Nilai Moral Dan Fungsi Cerita Tima dan Nima Cerita Rakyat Dayak Keninjal Kabupaten Melawi.” menghadiri dan mendoakan serta menyampaikan kebenaran Firman Tuhan dalam upacara tersebut. Nilai dan makna yang didapat dalam upacara betangkant anak ini adalah bahwa orang-orang harus saling mengasih, menerima satu sama lain sebagai wujud iman yang dipraktekkan di tengah-tengah masyarakat. Dengan demikian makna teologis dalam budaya betangkant anak adalah seperti karya Allah dalam Yesus Kristus yang memberikan anugerah keselamatan dan menjadi warga kerajaan Allah.

Jurnal Pendidikan dan Pembelajaran, 5 (2): $1-16$, http://jurnal.untan.ac.id/index.php/jpdpb/arti cle/view/14006/12545

Martono. 2010. "Sistem Religi Sastra Lisan Dayak Keninjal." Jurnal Pendidikan Sosiologi dan Humaniora, 1 (2): 148-165.

Martono. 2018. "Social Values Reflected In "Batu Dara Muning" An Oral Literature Of Dayak Keninjal Tribe." Journal of Education, Teaching and Learning, 3 (1): 34-36, http://journal.stkipsingkawang.ac.id/index.p $\mathrm{hp} / \mathrm{JETL} /$ article/view/459

Siswanto, K. 2017. "Perjumpaan Injil Dan Tradisi Jawa Timuran Dalam Pelayanan Misi Kontekstual." Evangelikal: Jurnal Teologi Injili dan Pembinaan Warga Jemaat, 1 (1): 61-66.

Sudarmono Otong, Wawancara Oleh Penulis, Madyaraya, 2019.

Tomatala, Y. 1996. Teologi Kontekstualisasi (Suatu Pengantar). Malang: Gandum Mas.

Undang-Undang Adat Istiadat dan Hukum Adat Dayak Kabupaten Melawi Kalimantan Barat, Hasil Musda Tanggal 29 November 2015. 